\title{
La imagen como prueba e invención en Solanas, una herramienta de descolonización cultural
}

Christian Pageau

UNNE

“(...) La utopia de una mirada que puede inventar un mundo" (Solanas, La Mirada, p.244)

\section{Resumen}

Este trabajo propone un estudio de la representación del subalterno en la cinematografia de Fernando E. Solanas. Partimos del concepto doble de imagen que sostiene el cineasta, es decir, la imagen como prueba y como invención. Demostramos que tanto en su vertiente documental como ficcional, este concepto doble no constituye un oxímoron, sino una sinergia. En un primer momento, acudimos a la idea de "esculpir en el tiempo" de Andrei Tarkovsky. Esta idea nos permite indagar en la esencia temporal del cine, y en la necesidad de capturar el tiempo. Abordamos la idea de tiempo nacional que sostiene Solanas, cercana al tiempo moral de Tarkovsky, la cual ayuda a entender su afán por una cine anclado en una cultura regional bien definida, pero también orientado por una moral, una ética de carácter político. Del cineasta, tomamos tres textos: "Hacia un Tercer-cine", y Cine, cultura y descolonización, escritos en colaboración con Octavio Getino y La mirada. Reflexiones sobre cine y cultura. Proponemos que estos textos tempranos del cineasta vehiculan propuestas éticas y estéticas todavía relevantes, en su esencia por lo menos, para el estudio de toda la cinematografia de Solanas. Por ejemplo, la necesidad de pasar por una renovación estética para poder lograr un cambio de sociedad. La renovación estética es presente en toda su obra. Su entrada en política activa es una muestra de su coherencia. Observamos además que estos textos anticipan o se inscriben en el discurso intelectual acerca de la descolonización cultural. Presentamos brevemente algunos conceptos propios de los estudios subalternos latinoamericanos : la subalternidad (John Beverley), un estado de subordinación que produce un ser sin historicidad, y la descolonización (Walter Mignolo), un esfuerzo para volver a re-autorizar al subalterno, y al mismo tiempo, renovar los paradigmas de interpretación de una realidad social y cultural. Si bien Solanas da lugar a las voces de los subalternos, se pone de su lado, se vincula y se implica en sus luchas, lo hace preservando para él el privilegio epistemológico. Sostenemos que su cine sirve para desvelar la subalternidad y permitir a su vez una cierta descolonización de la cultura. Concluimos que el concepto doble de Solanas permite lograr un cierto nivel de descolonización pero que difícilmente propone nuevos paradigmas. El corpus está compuesto por algunas películas tales como La hora de los hornos, Tangos, el exilio de Gardel, Sur y La dignidad de los nadies.

Palabras claves: subalternidad, descolonización, colonialidad del poder, epistemología, tiempo nacional. 


\section{Introducción}

El objeto del trabajo es empezar el análisis de la representación del subalterno en la cinematografía de Fernando E. Solanas. Partimos del concepto doble de imagen, es decir, imagen como prueba, e imagen como invención, sostenido por el cineasta. Queremos demostrar que tanto en su vertiente documental como ficcional, donde en realidad fusionan los géneros, este concepto doble no constituye un oxímoron, sino una sinergia. Sostenemos que sirve para desvelar la subalternidad y permitir a su vez una cierta descolonización de la cultura.

En un primer momento, acudiremos a algunas teorías del cine, y también a los escritos del propio Solanas para explicar la dualidad de su concepto de la imagen. Utilizaremos, por ejemplo, la idea de "esculpir en el tiempo" de Andrel Tarkovsky. De Solanas, tomaremos tres textos: Hacia un Tercer-cine, y Cine, cultura y descolonización, escritos en colaboración con Octavio Getino y "La mirada. Reflexiones sobre cine y cultura". Proponemos que estos textos del cineasta vehiculan propuestas éticas y estéticas todavía relevantes, en su esencia por lo menos, para el estudio de toda la cinematografia de Solanas.

En un segundo momento, a partir del análisis del corpus, demostraremos de qué manera trata la subalternidad y será preciso en ese momento presentar brevemente algunos conceptos: la subalternidad (John Beverley), y la descolonización (Walter Mignolo).

El corpus está compuesto por algunas películas tales como La hora de los hornos, Tangos, el exilio de Gardel, Sur y La dignidad de los nadies. Es importante mencionar que corresponden con períodos muy distintos en la biografia de Solanas como el inicio, el exilio, el retorno, marcados por cambios políticos en su vida que son muy contundentes.

\section{Naturaleza del cine en Solanas}

En su libro La mirada, Solanas en una entrevista con Horacio González presenta su visión del cine. Si bien el propósito del libro es de presentar una suerte de biografia del film Sur, los comentarios del cineasta revelan de manera más global algunos conceptos, ideas maestras o reflexiones personales sobre la ética y la estética cinematográfica que él aplica a su trabajo.

El capítulo 3, "Dialéctica de la mirada" es central para el estudio de su estética, sus definiciones del cine (de ficción) y de la imagen. En la sub-sección titulada "Invención de la imagen", se encuentra una primera definición: "La invención de una película no es la invención de una historia sino la invención de las imágenes" (Solanas 1989:83). Partiendo de esta definición, se entiende porque celebra la inventiva en la imagen durante la época muda del cine. $\mathrm{Y}$ de ahí toda una reivindicación del poder mágico de la imagen, de su poesía. Al respecto, cita al realizador brasileño Glauber Rocha, a quien dedica Sur, para subrayar la revolución poética que inició en América Latina al unir magia y poesía con teatro y cine (Solanas 1989:90). En un momento, hablando de la manera para un cineasta de conocer una realidad, Solanas categoriza al cine documental y al directo como la herramienta científica, y a la ficción como el modo poético. Pero demostraremos más adelante que la diferencia no es tan nítida, hay subjetividad en ambos géneros.

Puesto que el cine es la invención de imágenes, el siguiente paso lógico que se da es plantear que el cine es, en consecuencia, una alteración de la realidad. Solanas introduce esta 
idea al momento de confesar su inquebrantable "caza de imágenes" por todos los lugares de la ciudad, y la utilización posterior de éstas:

Ese proceso ininterrumpido de 'elecciones' de imágenes (...) es el largo proceso de transformación de la realidad. Es decir, el proceso por el cual uno crea o inventa sus propias imágenes y modifica la realidad". Los grandes autores (...) [construyen] otras imágenes de una nueva realidad, (...) revelan el conflicto y lo expresan por la vía poética. (Solanas 1989:89) (Subrayado mío)

Es decir que el cineasta, al elegir o ser elegido, quizás, por las imágenes registradas, ensambla fragmentos de la realidad y es este acto mismo que da vida a una realidad transformada, o mejor, a una otra realidad. El hecho, como siempre en el arte, consiste en partir de la vida real para producir una ficción que dé cuenta de la riqueza de la vida, una vida tan rica e inconmensurable que se requiere involucrar la imaginación para lograr explicarla. ¿No es la poesía (de las palabras, de las imágenes) el subterfugio más prodigioso para acceder a la realidad, a alguna verdad?

Volviendo a la distinción genérica en los films, Solanas alaba la revolución de Godard, subrayando que este "aparenta una estética documentalista pero inserta en la realidad sus propias imágenes al punto que lo singular y poético convivirán con la realidad cotidiana, revolucionando la mirada" (Solanas 1989:89). Aquí la "objetividad científica" del documental está utilizada en ficción produciendo cotidianidad y ficción, hay fusión de géneros. Se muestra la realidad al mismo tiempo que se la inventa.

El cineasta argentino insiste en varias oportunidades, ya lo vimos, en la creación por parte del realizador de imágenes propiamente suyas, en un arte que permite una búsqueda identitaria personal y, es lo más importante, una identidad colectiva, o sea, en su caso, una identidad especificamente nacional, para no decir nacionalista. Y está cuestión de cinematografia nacional está sostenida por la identificación y representación de un tiempo nacional, y sobre todo por el rol esencial que ocupa el tiempo en la construcción cinematográfica.

Atendemos primero a este tiempo nacional. "El tiempo es también una mirada y una cultura" nos dice Solanas (Solanas 1989:90). El tiempo nacional es de cierto modo la manera como la cultura va unida a un cierto fluir del tiempo y está enmarcada en un periodo histórico bien definido. En la larga década de los sesenta (Jameson), y quizás en las dos décadas siguientes, la cultura argentina es fuertemente nacionalista, es una herencia del peronismo. Frente a la invasión televisiva, a la avalancha de modelos hollywoodenses, dónde la imagen sólo cuenta para el montaje, donde las emociones fuertes y la intriga dominan, el tiempo de la vida está acelerado, entrecortado y el tiempo nacional esta pervertido. El efecto nivelador de la globalización, aportado por los medios masivos, diluye o reconfigura la esencia cultural nacional.

El cine "verdadero" permite, por su fidelidad al tiempo nacional, "captar el tiempo en el que los hombres viven" (Solanas 1989:90). En un impulso que nos podría parecer costumbrista, explica que toda cultura nacional tiene su tiempo, que podría encontrar su equivalente en las danzas y canciones nacionales. Después clarifica su posición al respecto 
Un cine se sentirá argentino (...) sino porque tome cuestiones argentinas o se exprese en nuestra lengua, sino que esencialmente tenga un sentido narrativo y una pulsación emotiva que se expresen en el tiempo social que le es peculiar. Es una visión antropológica del tiempo social y del tiempo estético. ...Se expresan en ese tempo cultural especifico. [Como en los realizadores argentinos] Torre Nilsson, del Carril, Birri, Favio, Soffici. (Solanas 1989:90)

Este comentario nos vuelve a la problemática de la naturaleza de la cultura, y la identidad argentina, un poco al modo de Borges en su ensayo "El escritor argentino y la literatura". Borges, aludiendo al Corán, observa que la pertenencia del libro a la cultura musulmana no implica, más bien prescinde de la presencia de objetos culturales estereotípicos como el camello. Por eso reivindica una cultura, una literatura sin exceso de color local, pero abierta a todas las culturas del mundo. El escritor reconoce su pecado de juventud, de haber ahondado en el costumbrismo. Solanas menciona a Borges, lo califica de mitrista'. Como el joven Borges, Solanas parece necesitar este color local, sobre todo en su uso de las coplas gauchescas en la narración de película como, por ejemplo, La dignidad de los nadies, dónde detona la lírica con la gravedad y lo crudo del tema de los subalternos, y su uso frecuente del tango. Pero como analizamos en otro trabajo ${ }^{10}$, lo hace de manera original, dando al tango un uso político, en Sur, y renovándolo al crear la tanguedia (un nuevo género dramático-musical, mezcla entre tango, comedia y tragedia) en Tangos, lo que constituye en si una innovación filmica, aunque se la pueda interpretar como destinada a la exportación. El uso del tango es también una manera de apelar a la cultura popular, a tratar de dirigir la película a un público de los sectores populares. Y en los dos, se nota la influencia cultural europa, sobre todo francesa.

Para Solanas, el arte del cine consiste en capturar el tiempo, y esta empresa define la identidad cinematográfica del cineasta y por consecuencia, la identidad nacional. Esta captación del tiempo es un ideal que toma de Tarkovsky, que estudiaremos a continuación.

\section{Capturar el tiempo}

Ahondaremos en esta sección en el aspecto esencialmente temporal del cine, acudiendo a Andreì Tarkovsky (la idea de esculpir en el tiempo) para poder caracterizar mejor los aspectos ficcionales y documentales en el cine de Solanas.

Solanas, al momento de explicar el rol de cineasta, refiere en varias ocasiones a Tarkovsky. De él, cineasta ruso de importancia mundial, rescata la idea del tiempo como materia o masa (mármol, granito) que el realizador tiene que esculpir para

\footnotetext{
${ }^{9}$ Solanas es quizás un poco injusto. Borges también está en contra de una idealización del gaucho. En su cuento "El Sur", Borges actualiza el mito del gaucho, al reservar una muerte casi inevitable al hombre culto de la ciudad que una serie de elecciones pequeñas pero decisivas, y quizás un exceso de romanticismo, llevarán a aceptar un duelo a cuchillo con un compadrito. Solanas no puede acusar a Borges, como lo hizo para Nilsson, de no actualizar el conflicto (Getino, Solanas 1973:93).

${ }^{10}$ Christian Pageau, El Sur como espacio identiario en Torres García, Borges y Solanas, capítulo 3, Memoría de maestría, Universiada de Montreal, 2010. Link papyrus UdM
} 
encontrar el tiempo singular (Solanas 1989:90) ${ }^{11}$. Esta idea esta desarollada en un libro de Tarkovsky, traducido al inglés con el título Sculpting in time, y al francés, Le temps scellé ${ }^{12}$.

En Sculpting in time, Tarkovsky, explica su metáfora del rol esencial del cineasta:

We could define it as sculpting in time. Just as a sculptor takes a lump of marble, and, inwardly conscious of the features of his finished piece, removes everything that is not part of it-so the film-maker, from a 'lump of time' made up of an enormous, solid cluster of living facts, cuts off and discards whatever he does not need, leaving only what is to be an element of the finished film, what will prove to be integral to the cinematic image. (Tarkovsky 1987:63)

Esta idea que inspira tanto a Solanas, por citarla tres veces en la conversación, da cuenta del carácter construido de la imagen cinematográfica. Es un trabajo artístico de depuración, que permite llegar a una unidad particular de tiempo identificado en una imagen o en todo el film. Ahora, habría que definir qué es un "pedazo de tiempo". Claramente para el cineasta, un pedazo de tiempo es un conjunto de hechos vivos, un trozo de la realidad captada por la cámara. Una imagen-prueba de la realidad que hay que trabajar, condensar para mostrar el tiempo real. En su sugerencia de un sistema de de la imagen, Tarkovsky insiste en que esta debe captar la realidad y por ende demostrar naturalmente su particularidad esencial y su poder de concentrar en si todo el mundo. La imagen debe mostrar la realidad, de manera sintética, y así se llegará a la perfección y a la belleza.

Otra cita nos ayuda a entender cómo se puede capturar el tiempo:

In what form does cinema print time? Let us define it as factual. And fact can consist of an event, or a person moving, or any material object; and furthermore the object can be presented as motionless and unchanging, in so far as that immobility exists within the actual course of time. (Tarkovsky 1987:63)

Un ejemplo en Tarkovsky es un largo plano-secuencia que abre la película Solaris. La cámara muestra el correr del agua produciendo el dulce baile de algunas hierbas acuáticas de una pequeña laguna. La escena sugiere el tiempo de la meditación, internalización e inquietud del héroe astronauta que está por embarcarse en un viaje espacial arriesgado en la órbita de Solaris.

Pero este tiempo es también vida, tal como lo explica el cineasta ruso:

\footnotetext{
"Solanas rescata esta idea de un documental de Leszczylowski, acerca de El sacrificio, un film importante de Tarkovsky (solanas 1989: 90). Dicho documental se encuentra en la web: http://avaxhome, ws/video/directed by andrei tarkovsky documentary.html

${ }_{12}$ Andrei TARKOVSKI, Le temps scellé. De L'enfance d'Ivan au Sacrifice, traduit du russe par Anne Kichilov et Charles H. de Brantes, Paris : Éditions de l'Étoile / Cahiers du cinéma, 239 pages, 1989.
} 
Time is necessary to man, so that, made flesh, he may be able to realize himselt as a personality. But I am not thinking of linear time, meaning the possibility of getting something done, performing some action. The action is a result, and what $\mathrm{I}$ am considering is the cause which makes man incarnate in a moral sense (Tarkovsky 1987:57).

Esta noción de tiempo moral se relaciona con la noción de tiempo nacional que desarrolla Solanas tal como lo vimos más arriba. Es decir, "captar el tiempo en el que viven los hombres", en el que se desarrolla su cultura significa captar el tiempo del desarrollo temporal y ético del hombre. Lucien Pelletier hace un comentario acerca del tiempo en Tarkovsky: " Il est le temps qui meut la dynamique spéculative du désir de bonheur, le temps de l'espérance (...) » (Pelletier, 137). Esta cuestión del deseo es explicita en Sur y también se relaciona con el tiempo nacional. Por ejemplo, en la motivación de los personajes, deseo del héroe Floreal por liberarse, deseo de amor del amigo francés, en el paralelo entre el deseo amoroso de la pareja principal (Floreal y Rosi) y el deseo de (re)construcción nacional (proyecto ProNaSur), la necesidad de reconocer y entender el deseo del pueblo, algo que los militares nunca quisieron o pudieron (sugiere Solanas) entender ${ }^{13}$. Todo el simbolismo de la "mesa de los suefios" donde se reunían los antiguos amigos peronistas para discutir del ProNaSur, ejemplifica esta noción de deseo, de tiempo nacional, un tiempo de deseo y esperanza en oposición a la censura dictatorial. Quizás se podría matizar este aspecto: a Solanas le interesa el hombre en tanto que perteneciente a una nación, y Tarkovsky, al hombre en el sentido general de la persona humana, pero la noción de tiempo moral o ético es común a los dos cineastas. $O$ quizás sea que Solanas parte de lo político, del anclaje de la memoria, un anclaje en un lugar y en un tiempo nacional. Lo moral y lo ético en Solanas remiten a lo político, expresado en el deseo de una nueva nación.

\section{3- Cine híbrido y descolonización}

Nos hemos ocupado hasta ahora de la imagen cinematográfica en Solanas, pasemos ahora al objeto de su cine, es decir, su motivación política. Veremos cómo la mezcla de géneros permite representar la subalternidad, des-encubrirla y operar una cierta descolonización.

\section{1-Subalternidad y descolonización}

Explicaremos brevemente las nociones de subalterno y descolonización. El subalterno es el "nombre para el atributo general de la subordinación (...) ya sea que ésta esté expresada en términos de clase, edad, género u oficio o en cualquier otra forma" (Beverley 2004: 27) ${ }^{14}$. Se completa así la definición: "Nosotros reconocemos, por supuesto que la subordinación no puede ser comprendida excepto como uno de los términos constitutivos de una relación binaria de la cual el otro término es el de dominación" (Beverley 2004:128). El subalterno es un sujeto sin

\footnotetext{
${ }^{13}$ Escena de la visita a los militares en el ProNaSur, proyecto nacional de desarrollo industrial en la pampa.

${ }^{14}$ En su libro, Subalternidad y representación, John Beverley, representante del Grupo de Estudios Subalternos Latinoamericanos, rescata de Ranajit Guha (del Grupo de los estudios subalternos del Sur asiático) la definición de lo subalterno.
} 
autoridad, ni cultural, ni histórica. Así, se subraya la necesidad de una nueva historiografia para devolverle su autoridad en tanto que sujeto histórico activo. Los intelectuales del grupo de estudios subalternos latinoamericanos coinciden en la necesidad de un nuevo orden mundial democrático y reconocen además los límites de la historiografia elite en relación con los subalternos. Por otra parte, tiene en cuenta que si bien se actúa sobre el subalterno, el subalterno también actúa sobre la sociedad.

La opción des-colonial que propone Mignolo se sostiene en una crítica radical de la categoria modernidad, al postular que trae natural y obligatoriamente consigo la colonialidad del ser y del saber ${ }^{15}$. Quijano habla de la "colonización del imaginario del dominado" (2007:169), y Mignolo llama este proceso "la subalternización del conocimiento" (2000:59). La hegemonía del imaginario colonial (y post-colonial) ha producido diferencias que no son culturales, sino más bien coloniales (2004:22). Detrás de la modernidad se encuentran la exterioridad y la heterogeneidad histórica estructural; la historia no es un recorrido lineal determinista del tiempo, al contrario, está reorganizada por la lógica del poder. Se requiere en este contexto pensar el mundo desde la diferencia colonial, a partir de los bordes de la ideología eurocentrada. El pensamiento fronterizo permite pensar la "pluriversalidad", sale de los bordes, del espacio de los marginalizados para volverse un proyecto epistémico, ético y político. Apunta claramente a un pensar otro, que proviene de lo subalterno, de un modo que se parece a la propuesta de Beverley. Mignolo habla entonces de construir "un mundo en el que quepan muchos mundos". En su libro, La idea de América Latina. La herida colonial y la opción decolonial, Mignolo presenta lo que entiende por decolonización partiendo de una interpretación de la modernidad en clave de colonialidad del poder, del ser y del saber, que producen a su vez una geopolítica del conocimiento. Sencillamente dicho, promueve la interpretación del mundo a partir de nuevas epistemologías, o sea, de nuevos locci de enunciación.

\section{2-La descolonización en Solanas}

\subsection{1-Los textos}

En el manifiesto seminal, Hacia un Tercer-Cine, (1966-68) co-escrito por Octavio Getino y Solanas, escrito después de La hora (1969), los autores plantean de manera clara la diferencia entre su cine revolucionario y el cine uniformizador y hegemónico hollywoodense. Es un cine "imperfecto" en el sentido de García Espinosa, que se opone al Primer-Cine, el cine "perfecto", basado en imágenes captadas para el montaje, para provocar emociones fuertes, imponiendo al nivel mundial la dictadura del cine de distracción, una pedagogía de la aculturación y de la despolitización. El Tercer-Cine implica la "destrucción de la imagen que el neocolonialismo ha hecho de sí mismo y de nosotros [y la] construcción de una realidad

\footnotetext{
${ }^{15}$ La colonialidad del poder es una noción de Aníbal Quijano. Propone que se sostiene en América Latina y en otras regiones que fueron colonizadas, en la imposición de una clasificación social de la población según criterios de raza. Dicho de otra manera, la hegemonía moderna impone una perspectiva binaria Oriente-Occidente, primitivo-civilizado, y por extensión, mágico/mítico-científico, irracional-racional, tradicional-moderno (Quijano 1991:239). Esta colonialidad del poder se manifiesta en la definición del ser y la producción del saber según epistemologías eurocentradas, negando la historicidad local propia latinoamericana, dando lugar a la colonización del ser y del saber.
} 
palpitante y viva, rescate de la verdad en cualquiera de sus expresiones" (Getino, Solanas 1968:7). Esto requiere la creación de un hombre nuevo, y un mundo nuevo. Este raclamo por la destrucción de un imaginario impuesto y la creación de uno propio es un acto de descolonización. La idea de un cine-acto es la de un cine politico que "puede transformar la convocatoria en una especie de acto político, en lo que según Fanon podría ser 'un acto litúrgico, una ocasión privilegiada que tiente al hombre para oír y decir" " (Getino, Solanas 1968:21). Esta manera de crear un nuveo espacio de diálogo, algo que podría convertirse en una nueva arena política consiste también un acto descolonizador, puesto que permite rescatar y valorizar la opinón del subalterno.

En el libro Cine, Cultura y descolonización, los autores Solanas y Getino destacan "el papel del cine y de los realizadores cinematográficos (...) en el proceso de liberación de los países dependientes, particularmente la Argentina" (Getino, Solanas 1973:5). Se presenta como "un testimonio más de una de las tantas experiencias de descolonización y de entronque con el movimiento de masas argentino" (Getino, Solanas 1973:7). Destaca la necesidad de descolonizar la cultura, dejar de "pensar con el pensamiento del otro" (Getino, Solanas 1973:105). En lo cultural, se denuncia la ausencia de las masas en las interpretaciones históricas, ejemplificado en la adopción como modelo nacional por parte de la élite de versiones demasiado romantizadas o ilustradas, de algunos textos fundacionales. Así, el Martin Fierro, del cineasta Torre Nilsson constituye según les autores, una "castración del pensamiento de Hernandez" (Getino, Solanas 1973: 95). Dicho de otro modo, se denuncia la dicotomía barbarie-civilización como eje interpretativo y se propone en reemplazo la oposición dominador-dominado (neocolonizador aristócrata-masas neocolonizadas, es decir masas aculturadas y despolitizadas). Inspirándose entre otros en Hernández Arregui, Getino y Solanas denuncian el imperialismo económico que tiene una consecuencia cultural directa, es decir la auto-colonización de la elite ${ }^{16}$.

\subsection{2-La hora de los hornos}

El film La hora de los hornos es normalmente calificado de documental, pero proponemos que tiene rasgos de construcción que lo acerca a la ficción. Sus autores de hecho lo califican de "film-acto". La postura de los autores es claramente pro-peronista y revolucionaria. Se enmarca en el contexto histórico de la resistencia peronista a la opresión, desde la "Revolución Libertadora", derechista y autoritaria, que coicidió con la derrota de Perón en 1955, hasta la dictadura de la "Revolución Argentina", iniciada por Onganía (1966-1973). En el contexto intelectual latinoamericano de la época, dominan la teoría de la dependencia, y la propuesta de la teología de la liberación.

La ficción-documental presenta un formato original y complejo, reúne archivos, entrevistas, y fragmentos de otras películas como "Tire die" de Fernando Birri. Presenta también documentos filmados en varias partes del país entre 1965 y 1968 por los autores. El subtítulo es "Notas y testimonios sobre el neocolonialismo, la violencia y la liberación". El tono

\footnotetext{
${ }^{16}$ Hernández Arregui, en Imperialismo y cultura, ya en 1957 decuncia el imperialismo sostenido en un poder agricoéconomico y su efecto en la colonización de y por la elite, como el en caso de la revista Sur, y en su análisis de Borges, Sábato, etc.
} 
es denunciador e irónico, su ideología maniquea (King 2000:87), y presenta una versión revisionista de la historia (Mestman 2003:121). El documental se encuentra en la confluencia de las vanguardias políticas y artísticas, opuesto al cine de divertimiento de Hollywood. El carácter del film, por su forma y su discurso, es altamente subjetivo, se asemeja a un manifiesto y a un panfleto por su tono revolucionario, y por el hecho de acudir a la agitprop ${ }^{17}$.

La originalidad de la forma proviene en algunos casos de la publicidad: montaje rápido y corto, imágenes de doble sentido, impactantes, archivos yuxtapuestos de contenido opuesto. En la primera parte, se representa a Argentina a partir de una concentración de la miseria, da una imagen transformada de la realidad argentina: se ve lo peor del interior, como si fuera África o Argelia, en una manera que sobrecarga la subalternidad. La segunda parte es una alabanza al peronismo y su líder, representante y padre de los trabajadores, en plena época "gorila"18 dominada por la élite de derecha. La tercera parte justifica el recurso de la violencia por el pueblo oprimido.

Un hecho interesante que contrasta con el didactismo abrupto del film es la invitación al diálogo. Se presentan espacios vacios sin sonido ni imagen que invitan al debate entre espectadores, incitan a pasar a la acción. La película rescata de Frantz Fanon la frase conocida: "todo espectador es un traidor". Es decir que el espectador debe volverse combatiente.

Claramente, la forma no es sólo del documental; los recursos técnicos y la construcción narrativa conforman una estética híbrida. Y se explica esta innovación por el deseo profesado de cambiar la realidad social, de luchar contra el imperialismo cultural y económico. El contexto de dominación y aculturación neocolonial justifica los medios, la meta es la liberación. Una nueva ética requiere una nueva estética. La descolonización en el sentido de Solanas consiste en liberar la nación, las masas, de un imaginario cultural y político que no es el suyo y que lo aliena y lo empobrece. Propone, en la mudanza intelectual de la época, izquierdista por esencia (Gelman), otro paradigma, el que parte de "el pueblo", pero desde el discurso de los intelectuales. Así, la manera de hacerlo implica para el cineasta hablar "por el pueblo", no hacerlo hablar. Solanas desde un discurso nuevo pero vertical, habla de los oprimidos y enseña la "única" vía posible, la revolución, en una inspiración guevarista.

Su presentación de la historia argentina y latinoamericana puede ser calificada de revisionista, pero permite en este momento histórico una visión desde los vencidos, desde los subalternos, en oposición a la versión oficial de la época, o por lo menos una toma de partido por el subalterno. Es cierto que es una película que tiene un anclaje político histórico muy específico, el contexto izquierdista intelectual y por ende, revolucionario de la larga década de los sesenta. Es una película marcada por el contexto histórico, no es atemporal, por su carga

\footnotetext{
${ }^{17}$ La palabra proviene del ruso y se traduce por "agitación y propaganda". Es la contracción del nombre del Departamento de Agitación y Propaganda instaurado por el Partido Soviético Comunista en los años 1920. Su objetivo es de controlar y promover el condicionamiento ideológico de las masas y reviste formas diversas (Tate). Está asociada a una forma de teatro cuyo objetivo es sensibilizar un público a una situación política o social. Apareció en Rusia después de la Revolución de 1917. Sus temáticas incluyen la crítica de la burguesía, promoción del marxismo, socialismo o comunismo (Larousse).

${ }^{18}$ Argentinismo, significa de manera general el desprecio de las masas. Esta vínculado con un contexto internacional donde la derecha dirigente de Occidente se inquieta por la preservación de sus prerrogativas visto el incremento de democracia que alcanza de manera efectiva hasta las capas humildes. Según el DRAE: 4. m. despect. coloq. Arg., Cuba, Ur. y Ven. Individuo, casi siempre militar, que toma el poder por la fuerza.
} 
ideológica y su aspecto didáctico. Aún así, la toma de partido por el subalterno se repite a lo largo de la filmografia de Solanas.

Según comenta Beverley, inspirándose en Chakrabarty, la historiografia de los estudios subalternos no es la historia desde abajo, difiere de esta en tres áreas:

(a) una relativa separación entre la historia del poder, y de cualquier historia universalista del capital, (b) una crítica de la forma nación, y (c) una interrogación de la relación entre saber y poder (y por ello del archivo mismo y la historia como una forma de saber). (Beverley: 13)

Es decir, como lo propone Mignolo, que hay que interpretar la historia desde la colonialidad del poder. Parece que Solanas acierta en este punto de separar la historia del poder y la del capital. El punto de la crítica de la categoría nación es más problemático. Solanas crítica la forma de la nación impuesta por los regímenes dictatoriales pero no disputa la categoría nación en sí, al contrario, quiere y fomenta una concepción nacional de la política y de la identidad cultural. Según los criterios de Mignolo, su propuesta no sería suficiente en tanto acto descolonizador porque cambia los términos de la conversación pero no el contenido. Aún así, el hecho de cambiar el paradigma sarmentino por otro, el de dominador-dominado, ya parece ser un paso hacia una nueva epistemología. Es una cuestión por profundizar. Su forma de interrogar la relación entre poder y saber es demostrando la aculturación del pueblo mediante la elite burguesa, algo bien explicado en Hacia un Tercer-Cine y en Cine, cultura y descolonización.

¿Qué representación hace Solanas del subalterno? En La hora, lo representa como víctima, pero lo incita a ser responsable de su devenir político. Lo representa también en tanto héroe, aludiendo a los liberadores latinoamericanos como San Martin, o a los héroes de las revoluciones latinoamericanas. También lo presenta como ciudadano politizado, protagonista de manifestaciones y confrontaciones, un combatiente político.

\subsection{3- La dignidad de los nadies}

Pasamos ahora a analizar brevemente otra película, de 2004, La dignidad de los nadies, más cerca del documental clásico pero todavía bastante "construida". Su contexto se inicia en la crisis financiera de fines de 2001 (el corralito) que degeneró en crisis política. De manera general, se inscribe en el contexto de neoliberalismo y mundialización, dónde neoliberalismo coincide con neopopulismo (Weyland). Es el momento de aparición de nuevas izquierdas en América Latina, un rasgo que fue otorgado, en un momento inicial, al primer kirchnersimo. Corresponde también a una actividad política intensa de Solanas. En este film, la imagen se combina al tratmiento de las voces. Las imagenes son más bien pruebas de la realidad, su construcción se manifiesta sobre todo en el enfoque de la camara, la división en capítulos, y la inserción de intertítulos. La ficción-documental de Solanas rescata las voces de los nadies, y al hacerlo, los representa como héroes cotidianos, a través de sus hazañas cotidianas y su solidaridad colectiva. Toma la forma de una serie de cortos metrajes unidos por la voz narrativa del cineasta. Subrayamos algunos puntos que apuntan a cierta ficcionalización. Primero la intervención del cineasta. Los varios episodios toman la forma de diálogo libre donde no se suele ver el que entrevista, pero se lo oye, y dónde la voz de la persona entrevistada está priviligiada, como un diálogo que se daría un aire de monologo, pero que sí tiene valor de testimonio. Aún así, la voz del cineasta interviene para orientar la "conversación". Por sus 
prenguntas o comentarios cortos, acentúa el drama contado por el "nadie", enfatiza el estado anímico del protagonista, el subalterno, olvidado por el estado y la sociedad. Por otro lado, se ve al cineasta en dos capítulos, es decir, en el campamento de los piqueteros, y en le comedor popular. Las múltiples voces narrativas, es decir, las de Solanas y las de los nadies componen una "plurifonía" narrativa que renueva la voz narrativa clásica del narrador único e omnisciente ${ }^{19}$. Solanas cuenta y al mismo tiempo rescata testimonios. Hay un cruce entre ficción y realidad. Hay marcas de construcción narrativa sobre todo entre los dos primeros episodios, cuando el protagonista del primer episodio, el escritor motoquero se encuentra con su amigo El Toba, que protagonizará el segundo episodio. Como en La hora, Solanas incluye su interpretación de la realidad socio-política, denuncia las políticas neoliberales inciadas con el mememismo. Destaca la voz autorizada del cineasta-político, una figura muy pública y política, que crítico publicamente a Menem, fue diputado entre 1993-1997, creó un partido político, Proyecto Sur, etc.

Un hecho importante, a diferencia de La hora, La dignidad incorpora la voz del pueblo. Pero el diálogo, como vimos, no es exento de guión. Es importante observar que en oposición a la historia oficial, que tiende a silenciar, detrás de estadísticas anónimas las voces y la vida de los pobres o marginados, si bien la película relata y cuenta, también rescata testimonios individuales y colectivos, historias y memorias particulares. Cómo se comentó arriba, es un paso en la dirección de una descolonización de la representación. Se puede ver un intento de presentar otra historiografia, como lo sugiere Beverley, protagonizada por los subalternos. Por otro lado, cabe preguntarse si presentar ejemplos de las actividades de las asambleas, de la acción de los piqueteros, de las iniciativas individuales dentro de instituciones como un hospital y un colegio públicos tendría un efecto descolonizador. Obviamente, no tanto como la acción misma en el terreno. ¿Pero qué más puede hacer un cineasta?...Hacer política activa, como lo inicio Solanas en 1993 como Diputado Nacional de Frente Grande en Buenos Aires. Y todavía acá se abre todo un capítulo del análisis de su obra política que debería ocupar otros trabajos. En cuanto a nosotros, podemos pensar en la manera en qué su actividad política pudo haber influenciado en su trabajo concomitante como cineasta. Proponemos que el discurso del cineasta se hace más pragmático, deja de lado la ficción para volver a la capacidad objetiva del documental; pero que permite también su dosis de ficcionalidad y conserva cierto didactismo (La Última estación, Oro Impuro). Las últimas películas, a partir de Memoria del saqueo se pueden ver como una herramienta para communicar con el electorado los ideales y proyectos que sostienen su programa político.

\subsection{4-Tangos, el exillio de Gardel y Sur}

Volvemos a películas más claramente ficcionales, como es el caso del díptico conformado por Tangos, el exilio de Gardel y Sur. El contexto histórico de referencia es el Proceso de 1976-1983, y el contexto de elaboración coincide con el exilio del cineasta durante

\footnotetext{
${ }^{19}$ Pablo Piedras analiza el protagonismo del cineasta en su producción documentalista del siglo XXI. Observa que el cineasta, a pesar de colocarse al lado del protagonista, para representarse como parte del conflicto, con voluntad de cambiar la realidad, sigue manteniendo la autoridad textual y el control sobre el sentido del discurso (Piedras 2011: 667).
} 
este periodo, y la vuelta a la democracia. El díptico trata del exilio exterior y del exilio interior, respectivamente, y es también una denuncia de las censuras de las dictaduras. Pero es un cine bastante melancólico, también con un anclaje temporal muy particular, la experiencia del exilio y del retorno del cineasta. Además, se lo podría calificar, quizás, de cine para la exportación, para un mercado de espectadores europeos que puedan entender las imágenes y representaciones del exilio. Al nivel estético acude a mucho simbolismo: los papeles, el humo, los maniquíes. Estos aluden entre otros al peronismo, las manifestaciones, la censura, el sueño, el pasado, a la confusión entre realidad y sueño, presente y pasado. Se observa además una teatralización del cine, y el protagonismo de fantasmas. Todo ello sirve el propósito de ir en contra de los esquemas rígidos de Hollywood, aunque adoptando algunos trucos del "enemigo", por ejemplo el musical. También tiene un carácter descolonizador, quizás parcial. Permite dar cuenta de lo ocurrido durante la dictadura, revertiendo así la censura del cuerpo y de la palabra, produciendo una catarsis para todos los exiliados. Permite una reflexión crítica sobre la sociedad, propone mirar hacia el futuro con un poco de esperanza, en el deseo de amor de una nación, en el deseo de la nueva generación. Acudir al tango y sus figuras míticas (aparición de los fantasmas de Gardel, y Discépolo, ancianos, un poco desengafiados, con mirada retrospectiva) es un modo de recordar que los argentinos, en unas oportunidades, también fueron grandes. Acudir a San Martín, en Tangos, es también representar al héroe como figura mítica desterrada, no comprendido, una cierta manera de criticar la nación que lo olvidó. Pero en general, nos parece que no se cuestiona tanto la categoría nación, sino que se acude a mitos nacionales para fortalecer una comunidad cultural regional. Solanas propone unir el sentido de símbolos culturales con un significado político. En Sur, el otro se ha vuelto lo mismo, los subalternos son todos los ciudadanos sometidos a las censuras, son los ciudadanos exiliados en su propio país. En Tangos, los subalternos son los exiliados exteriores, del Río de la Plata, en París, juntos con el amigo francés, exiliado interior. Si bien se representa su miseria, se relata también sus logros.

Se podría preguntar en este caso si la representación que hace Solanas de los exiliados no les conformara en su categoría de subalternos, quizás sea el caso, pero, por lo menos, se hace en el sentido de una denuncia política, y el díptico "muestra" actos de descolonización, protagonizada por subalternos, como una huelga en un frigorífico, y una manifestación en París contra la desaparición de artistas argentinos durante el Proceso.

Gayatri Spivak se pregunta si puede hablar el subalterno, y, si podemos resumir su pensamiento complejo, contesta que no (Beverley: 5). En todo caso, no de una manera que tenga autoridad o sentido para nosotros (¿la elite, la academia?); no, sin modificar el orden poder-saber que lo conforma como tal. De cierto modo, la censura que sufrió Solanas y varias de sus películas, muestran que su discurso, que protagoniza mucho los subalternos, irrumpe de una manera no deseada por la élite dirigente. Dando a conocer historias individuales y revisando la historia nacional, al poner en escena los subalternos, Solanas construye, con mezcla de ficción y documental una imagen por lo menos válida de la subalternidad. Por otra parte, este mismo rasgo de construcción, intervención del autor y auto-representación podrá parecer intrusivo, y al hablar por el subalterno, cae quizás en la trampa, la paradoja constitutiva de los estudios subalternos, es decir, cómo hablar del subalterno desde la academia (o la elite, a la cual pertenece Solanas) sin volver a confirmarlo en su estatuto. 
La cuestión de descolonización implica, según Mignolo, la puesta en duda de la capacidad de la nación y hasta de la modernidad misma de responder a la pregunta del vivir juntos, en sociedad. La propuesta es radical, implica la búsqueda de nuevos paradigmas, en los subalternos. La ética y la estética de Solanas son nacionalistas, no sugieren otra forma de gobierno sino una mejor manera de hacerlo dentro del Estado. Pero Solanas no está tan alejado del cuestionamiento posmoderno que se hace a la modernidad. Identifica el neoliberalismo a la forma actual de colonialismo ${ }^{20}$. En su último. libro Causa Sur, presenta un proyecto político nacional, basado en el desarrollo y la reapropiación de los recursos naturales, y el mejoramiento de leyes sobre medios de comunicación y cultura, entre otros, pero no menciona otros modos de gobierno como ocurre en Ecuador o Bolivia. Tampoco Argentina es un país andino con fuerte población indígena donde chocan cosmovisiones distintas. Pero sí, habla de reconstruir el Estado, "darle un nuevo contenido y sentido a esa participación estatal (...) devolver al país al estado de justicia" (Solanas 2009: 321). Él persigue el deseo de una nación fuerte y protectora. En un periodo de cuestionamiento del rol del estado, de su debilitamiento frente a las entidades económicas y políticas trasnacionales, quizás el Estado queda como el único amparo para el frágil ciudadano.

\section{Conclusión}

Este trabajo quiere ser propositivo y servirá para profundizar las cuestiones de subalternidad y descolonización, que a su vez implican indagar en categorías como modernidad, nación, sociedad civil, ciudadanía, etc. Por lo menos, hemos intentado demostrar que en el cine de Solanas, las películas son a la vez ficcionales y documentales; el cineasta logra crear un género híbrido. En cuanto a su eficacia en tanto herramienta de descolonización, si se entiende el término en el sentido que le da Mignolo, la descolonización no siempre sería tan bien lograda. Solanas se sitúa argumentativamente del lado de los subalternos, al re-presentar sus reivindicaciones, pero su método cinematográfico supone la preservación de un privilegio epistémico para él que habla desde el lugar enunciativo de la autoridad. Lo que hay que buscar son nuevos paradigmas.... Volvemos así a la esencial problemática del subalterno. Sería interesante pensar al subalterno para ver cómo se puede representarlo o modelizarlo en la sociedad, o en el mundo, en tanto contra-hegemonía, como "El Pueblo" en Gramsci, que parece ser el modelo de Solanas del primer periodo, o como García Canclini, una "comunidad interpretativa de consumidores", que sería un modelo para la época de los massmedia y del neoliberalismo menemista. Otro modelo tendría que tener en cuenta la globalización y la simultaneidad, y otro la conformación de identidades ficticias gracias a redes sociales virtuales. Pero tampoco se trata de representar sólo por representar. Beverley y Mignolo, a pesar de puntos de vista distintos, concuerdan en la necesidad de una implicancia política en el momento de pensar al subalterno.

\footnotetext{
${ }^{20} \mathrm{Al}$ analizar la gestión nacional de los contratos de yacimiento de gas, en el caso de Loma La Lata, por ejemplo, habla de "colonialismo del convenio" (Causa Sur, p.324).
} 


\section{Referencias}

BEVERLEY, John. Subalternidad y representación: debates en teoría cultural, traductores M. Beiza y S. Villalobos-Ruminott; Madrid: Iberoamericana; Frankfurt am Main: Vervuert, 2004. GETINO, Octavio; SOLANAS, Fernando. Hacia un Tercer-Cine. Octubre 1968.

--.. Cine, cultura y descolonización. Buenos Aires: Siglo Veintiuno Argentina editores, 1973. HERNÁNDEZ ARREGUI, Juan José (1957). Imperialismo y cultura, Buenos Aires: Ediciones Continente, 2005.

KING, John. Sur: a study of the Argentine literary journal and its role in the development of a culture, 1931-1970. Cambridge: Cambridge University Press, 1986.

MESTMAN, Mariano. "La hora de los hornos, The Hour of The Furnaces" en Alberto ELENA; Marina Día Lopez, (eds.). The Cinema of Latin America. London: Wallflower Press, 2003, p.119-129.

MIGNOLO, Walter. La idea de América Latina. La herida colonial y la opción decolonial. Barcelona: Gedisa, 2007.

----. Local Histories-Global Designs. Coloniality, Subaltern Knowledges, and Border Thinking, Princeton, NJ: Princeton University Press, 2000.

PELLETIER, Lucien. "Compte-rendu,TARKOVSKI, Andrei, Le temps scellé. De L'enfance d'Ivan au Sacrifice », Laval théologique et philosophique, vol. 47, n 1, p. 135-137, 1991.

PIEDRAS, Pablo. "Fernando Solanas: esplendor y decadencia de un sueño político" en Ana Laura Lusnich, Pablo Piedras (ed.), Una historia del cine politico y social en Argentina. Formas, estilos y registros.(1969-2009), p. 661-674, Buenos Aires: Nueva Librería, 2011.

QUIJANO, Anibal. "Colonialidad del poder, eurocentrismo y América Latina" en R. Pajuelo y P. Sandoval (eds), Globalización y diversidad cultural. Una mirada desde América Latina, p. 228-281, Lima: Instituto de Estudios Peruanos, 2004.

SOLANAS, Fernando E. (Pino). Causa Sur. Hacia un proyecto emancipador de la Argentina. Buenos Aires: Planeta, 2009.

. La Mirada. Relfexiones sobre cine y cultura. Entrevista de Horacio González. Buenos Aires: Puntosur, 1989.

TARKOVSKY, Andreï. Sculpting in Time, 2nd edition, 1987.

http://www.scribd.com/doc/44512850/Andrey-Tarkovsky-Sculpting-in-Time-2nd-Edition-

1987.

WEYLAND, Kurt, "Neoliberalism and Democracy in Latin America : A Mixed Record". Latin American Politics and Society, 46,1: 135-157, 2003.

Apuntes y comentarios de la Dra. Silvia Hirsch, en el marco del seminario de posgrado "Alteridades Representadas. Cine y fotografia etnográficos", dictado en la UNNE, Facultad de Humanidades, 2010.

Filmografia:

-Solanas y Getino: La hora de los hornos (1966-1968).

-Solanas:

Tangos, El exilio de Gardel (1985), Sur (1988), La dignidad de los nadies (2005).

-Tarkovsky

Solaris (1972). 


\section{Nota biográfica del autor}

Christian Pageau es Magister en Artes (Estudios Hispánicos), Universidad de Montreal, Canadá. Memoria multidisciplinaria, conceptualiza el espacio Sur a partir de ideas de Michel Foucault y Walter Mignolo. Becado de los gobiernos de Quebec (FQRSC) y Canadá (CRSH). Alumno regular del doctorado de Letras, área literatura, UNNE. Tesis dirigida por Dr. Mariano Mestman, UBA, CONICET, concierne al estudio de la cuestión de la subalternidad en la obra de Fernando Solanas. Ha publicado sobre cuestiones de nuevas epistemologías, cine, y literatura. 